\title{
Expression of glutaredoxin (thioltransferase) in the rat ovary during the oestrous cycle and postnatal development
}

\author{
R González-Fernández¹, F Gaytán², E Martínez-Galisteo', P Porras', C A Padilla1, \\ J E Sánchez Criado ${ }^{2}$ and J A Bárcena ${ }^{1}$
}

Departments of ${ }^{1}$ Biochemistry and Molecular Biology and ${ }^{2}$ Cell Biology, Physiology and Immunology, University of Córdoba, Córdoba, Spain

(Requests for offprints should be addressed to J A Bárcena; Email: bb1 barua@uco.es)

\begin{abstract}
Glutaredoxins (Grxs) are low-molecular-weight proteins which participate in redox events in association with glutathione (GSH) and are involved in a variety of cellular processes. It is known that oxidative stress plays important physiological roles within the ovary. In the present study, we have prepared specific antibodies against rat Grx and have used them to localize the protein in the ovaries of rats during postnatal development and during the oestrous cycle, by immunohistochemical methods. We have also performed a quantitative analysis of Grx by ELISA and Western blotting in homogenates of whole ovaries of cycling and pseudopregnant rats. We have found a prominent presence of Grx in the oocytes and in corpora lutea $(\mathrm{CL})$ during developmental and oestrous cycle changes. Grx was absent from the oocytes in the first days of postnatal life when marked oocyte degeneration takes place, but its presence was very conspicuous in the cytoplasm of oocytes in healthy and attretic follicles in rats from 10 days of age onward, independently of the day of oestrous cycle. Follicular cells were negative. Grx immunostaining in the CL was strong in infiltrating macrophages and in a population of steroidogenic cells that survived the apoptotic burst in regressing $C L$ and in $C L$ remnants, but was faint or absent in young $C L$ of the current cycle and in $C L$ during pseudopregnancy. Grx content and oxidoreductase activity in whole ovaries increased significantly during the phase transition from proestrous to oestrous along the cycle. These results support a role of Grx in the maintenance of functional oocytes and in luteal cells surviving the regression process, probably as a consequence of the demonstrated deglutathionylating function of this protein in an antioxidant and antiapoptotic context.
\end{abstract}

Journal of Molecular Endocrinology (2005) 34, 625-635

\section{Introduction}

Reactive oxygen species (ROS) production is a normal process of cell metabolism. The imbalance of the redox status of the cell (oxidative stress), resulting from the accumulation of ROS due to the decrease of antioxidant defenses, is involved in apoptotic cell death and in several diseases such as rheumatic disease, arteriosclerosis, diabetes, cancer and AIDS (Jacobson 1996).

Glutathione (GSH), the predominant low-molecularweight thiol in mammalian cells, plays a central role in the defence against oxidative stress and is involved in all major cell functions including, proliferation, differentiation and apoptosis (Sies 1999).

The glutaredoxins (Grx) are low-molecular-weight proteins $(9-12 \mathrm{kDa})$ with GSH-disulfide oxidoreductase activity, and are structural members of the thioredoxin fold superfamily (Holmgren \& Aslund 1995). They catalyse the reduction of protein disulfides and GSH-protein mixed disulfides by means of the so-called deglutathionylase activity (Gravina \& Mieyal 1993). A new activity with putative important physiological implications has been discovered recently in which Grxs act the opposite way, that is, capturing the reducing power of reduced lipoamide to keep the GSH system in the reduced state (Porras et al. 2002). Grxs have been found in every type of organism, and several of them have been shown to contain a family of isoforms, which may localize to different subcellular compartments; for instance, there are nuclear (Rozell et al. 1993, Lundberg et al. 2001) and mitochondrial (Gladyshev et al. 2001, Lundberg et al. 2001, Pedrajas et al. 2002) Grxs. In mammals, there is a growing list of functions assigned to Grx with involvement in cell differentiation/ proliferation (Takashima et al. 1999), signal transduction (Bandyopadhyay et al. 1998, Hirota et al. 2000, Daily et al. 2001) and apoptosis (Chrestensen et al. 2000, Daily et al. 2001).

In the ovary, redox regulation plays a crucial role in the biological responses to oxidative stress. Redox homeostasis has been reported to prevent oocyte apoptosis and to be involved in the meiotic process and in the interaction of gametes at fertilization (Miesel et al. 1993, Sawai et al. 1997, Tatemoto et al. 2000). In addition, superoxide, hydrogen peroxide and lipid peroxides are generated within the follicle at ovulation, 
as well as in luteal tissue during both natural and prostaglandin-induced luteolysis (Tilly 1996, Tanaka et al. 2000, Behrman et al. 2001). In this context, redox regulation systems are expected to be highly expressed and tightly regulated in the ovary, to prevent the risk of ovarian disorder due to oxidative damage.

Grx has been associated with implantation in the human endometriun (Stavreus-Evers et al. 2002), cervical ripening during pregnancy (Lysell et al. 2003) and corpus luteum (CL) functionality (García-Pardo et al. 1999). Grx has also been detected in bovine ovary (Rozell et al. 1993). In this study, we have investigated the expression of Grx in the ovary of rats during postnatal development, and in adult rats during the oestrous cycle and pseudopregnancy, using polyclonal antibodies raised against rat Grx.

\section{Materials and methods}

\section{Animals}

Female Wistar rats were used. During postnatal development, groups of rats were killed at 3, 5, 7, 10, 20 and 30 days of age. Adult cycling rats, showing at least two consecutive 4-day oestrous cycles, as assessed by daily vaginal smears, were killed in each day of the cycle (at $0900 \mathrm{~h}$ ). Additional rats were killed at $0200 \mathrm{~h}$ in oestrus, when ovulation was imminent (Gaytan et al. 2002). Pseudopregnancy was induced by cervical stimulation in proestrus and oestrus, as previously described (Sanchez-Griado \& Rothchild 1986). Animals were killed on day 10 of pseudopregnancy. The effectiveness of pseudopregnancy induction was checked histologically by the presence of large fully luteinized CL. This research was approved by the ethics committee of the University of Córdoba (Spain) in accordance with current legislation on experimentation with animals, considering the origin and care of the animals used, the design and methodology employed, and the protocol that forbids suffering or unnecessary pain to the animals.

\section{Grx preparation and generation and characterization of anti-Grx antibodies}

Recombinant rat Grxl was cloned, overexpressed and purified by a procedure similar to that followed for human Grxl, as described elsewhere (Padilla et al. 1995, 1996). A rat liver cDNA library was used with a probe obtained by PGR with specific primers designed on the basis of homologies between human and mouse Grx. Overexpression in E. coli was carried out in pET-3d vector (Promega). Recombinant rat Grx was purified by repeated ion-exchange HPLC under reducing conditions. Purity was checked by SDS-PAGE. Polyclonal antibodies were obtained in new Zealand albino rabbits according to established immunization protocol (Harboe
\& Ingild 1983). Preimmune serum was obtained before the first inoculation. Antisera with high titres were pooled, and immunoglobulin $\mathrm{G}$ ( $\operatorname{IgG}$ ) was purified by affinity chromatography on Protein A-Sepharose. Further purification was achieved by immunoaffinity chromatography on immobilized rat Grx-Sepharose.

\section{Preparation of crude extracts and Grx activity assay}

Freshly dissected ovaries and livers from every group of adult cycling and pseudopregnant rats were homogenized with an Ultra Turrax homogenizer in two volumes of chilled TE buffer $(50 \mathrm{mM}$ Tris- $\mathrm{HCl}(\mathrm{pH} 7 \cdot 6)$ and $1 \mathrm{mM}$ EDTA) containing $1 \%(\mathrm{w} / \mathrm{v})$ PMSF. The supernatant was obtained by centrifugation at 12000 r.p.m. for $30 \mathrm{~min}$ and was stored at $-80^{\circ} \mathrm{C}$ until analysis. Protein was determined by the method of Bradford with ovalbumin as standard (Bradford 1976), and Grx enzymatic activity was measured with the HED standard assay (Luthman \& Holmgren 1982). One unit of enzymatic activity is defined as the oxidation of $1 \mu \mathrm{mol}$ NADPH per min.

\section{Grx immunoblotting and ELISA}

SDS-PAGE was performed by the method of Laemmli on homogeneous 15\% acrylamide gels followed by Coomassie staining or electrotransfer to nitrocellulose membranes $(0.22 \mu \mathrm{m})$ and processed by the method of Towbin (Towbin et al. 1979). Tissue extracts were adjusted to normalize their protein contents, and $15 \mu \mathrm{g}$ were loaded into each well. Each gel carried at least two lanes loaded with different known amounts of pure Grx as internal standards. Immunoaffinity-purified antibodies were used at 1:200 dilution and developed with the ECL reagent (Amersham). The resulting chemiluminiscence was quantified with a Gnome detection system (Syngene, Cambridge, Cambridgeshire, UK) and compared with the standard curve.

A direct, non-competitive, 'sandwich type' ELISA method was developed; 96-well plates were coated with immunoaffinity-purified anti-rat Grx antibody (5 mg/ $\mathrm{ml}$ ), and after blocking with $2 \%$ skimmed milk, samples, or pure rat Grx for the standard curve, were added and incubated overnight at $4{ }^{\circ} \mathrm{C}$. Biotinylated anti-rat Grx was added, and streptavidin-peroxidase conjugate followed by pNPP as substrate was used to develop the assay. $\mathrm{A}_{405}$ was measured and the data were processed with KC Junior software (Bio-Tek, Winooski, VT, USA). Calibrating curves were obtained by the logit-log regression (Shaw et al. 1977).

Data are presented as mean \pm S.D.; statistical analysis was done by ANOVA with the Bonferroni-Dunn test and Student's $t$-test. Probability values less than $P<0 \cdot 05$ were considered statistically significant. 


\section{Immunohistochemistry}

The ovaries were dissected and fixed for $24 \mathrm{~h}$ in either Bouin-Hollande $(\mathrm{BH})$ or $4 \%$ paraformaldehyde (PFA) in Sorensen buffer. After dehydration, the ovaries were processed for paraffin-wax embedding. Sections $(5 \mu \mathrm{m}$ thick) were cut and placed on poly-L-lysine-coated slides.

Ovarian sections were dewaxed and incubated in $2 \%$ hydrogen peroxide for $30 \mathrm{~min}$ to quench endogenous peroxidase. After rehydration and washing in PBS, sections were incubated with normal rabbit serum to inhibit unspecific binding. After washing in PBS, sections were incubated overnight with the first (anti-rat Grx diluted 1:5) antibody at $4{ }^{\circ} \mathrm{C}$ in an humidified chamber. Negative controls corresponded to sections incubated with PBS, preimmune serum or anti-Grx antibodies preincubated with pure rat Grx, instead of the first antibody. The ABC method for detection of bound antibodies was routinely used. Some sections were immunostained for the macrophage marker ED1, as previously reported (Gaytan et al. 1998).

The different types of ovarian follicles were recognized by previously established criteria (Osman 1985). The different generations of corpora lutea (CL) were recognized by the proportion of non-steroidogenic to steroidogenic luteal cells, as previously described (Gaytan et al. 2001).

\section{Results}

\section{Immunohistochemical demonstration of Grx expression}

Positive Grx immunostaining was observed in both $\mathrm{BH}-$ and PFA-fixed tissues (Fig. 1A and B), and comparison of cellular location with both fixatives was consistent. However, unspecific background staining was considerably higher in BH-fixed tissues; therefore, PFA-fixed tissues were used. Preincubation of the antibodies with the peptide completely abolished immunostaining (Fig. 1C).

\section{Grx expression in the rat ovary during postnatal development}

Grx immunostaining was absent in the ovaries of neonatal rats at 3 and 5 days of age (Fig. 1 D). At this age, oocytes were organized in cords at the outer ovarian zone, whereas small growing follicles were present at the inner zone (Fig. 1D). At 7 days of age, small, growing follicles were more abundant, and slight Grx immunostaining was found in the cytoplasm of some oocytes (Fig. 1E). Degenerating oocytes were frequently observed, and were particularly abundant on postnatal day 3 (Fig. 1D). In juvenile rats, at 10 and 15 days of age, clear Grx immunostaining was found in the cytoplasm of oocytes. Immunostaining showed a punctate pattern and was found in both primordial and early growing follicles (Fig. 1F). From 10 to 20 days of age, the intensity of immunostaining paralleled follicle growth (Fig. $1 \mathrm{G}$ ), and was present in the oocytes of both healthy and atretic follicles (Fig. $1 \mathrm{H})$. A similar immunostaining pattern was found in 30-day-old rats. The granulosa and theca layers of growing follicles, as well as the surrounding ovarian stroma, were negative.

\section{Grx expression in adult cycling and pseudopregnant rats}

Oocytes were immunostained, independently of the day of the oestrous cycle. In primordial and early growing follicles, immunostaining in the cytoplasm of oocytes showed a punctate pattern (Fig. 2A and B). The intensity of the immunostaining increased in parallel to follicle growth, and was present throughout follicle development (Fig. 2C and D). Strong immunostaining was also present in the oocyte cytoplasm at $0200 \mathrm{~h}$ in oestrus, after the preovulatory luteinizing hormone surge, when ovulation was imminent (Fig. 2E).

Grx expression in CL was dependent on the age of the CL and varied among the different CL generations. In CL of the current cycle (from oestrus to proestrus), steroidogenic cells were negative, although the scarce infiltrating macrophages were immunostained (Fig. 3A). Macrophages were identified by their morphological features, the presence of phagocytized material and comparison with parallel sections immunostained for the macrophage marker ED1 (data not shown). The marked presence of Grx in infiltrating macrophages found here in CL was also found in bovine spleen germinal centres (Rozell et al. 1993). On the day of oestrous, the CL of the previous cycle showed abundant apoptotic cells and Grx-positive macrophages containing phagocytized apoptotic cells (Fig. 3B and C). A fainter immunostaining was present in the steroidogenic cells surviving the apoptotic burst (Fig. 3B and C). In CL of previous generations that underwent second or third apoptotic bursts, Grx immunostaining was stronger (Fig. 3D). A considerable heterogeneity for the intensity of immunostaining was observed in these regressing CL (Fig. 3D), as well as in CL remnants (Fig. 3E). The steroidogenic cells in the GL of pseudopregnancy did not show Grx immunostaining.

\section{Quantitation of Grx in adult cycling and pseudopregnant rats}

Crude extracts from ovaries of adult cycling rats were used to determine precisely the amount of total Grx. As a reference, crude extracts from the livers of the same animals were also analysed to establish possible background variations in Grx contents. 


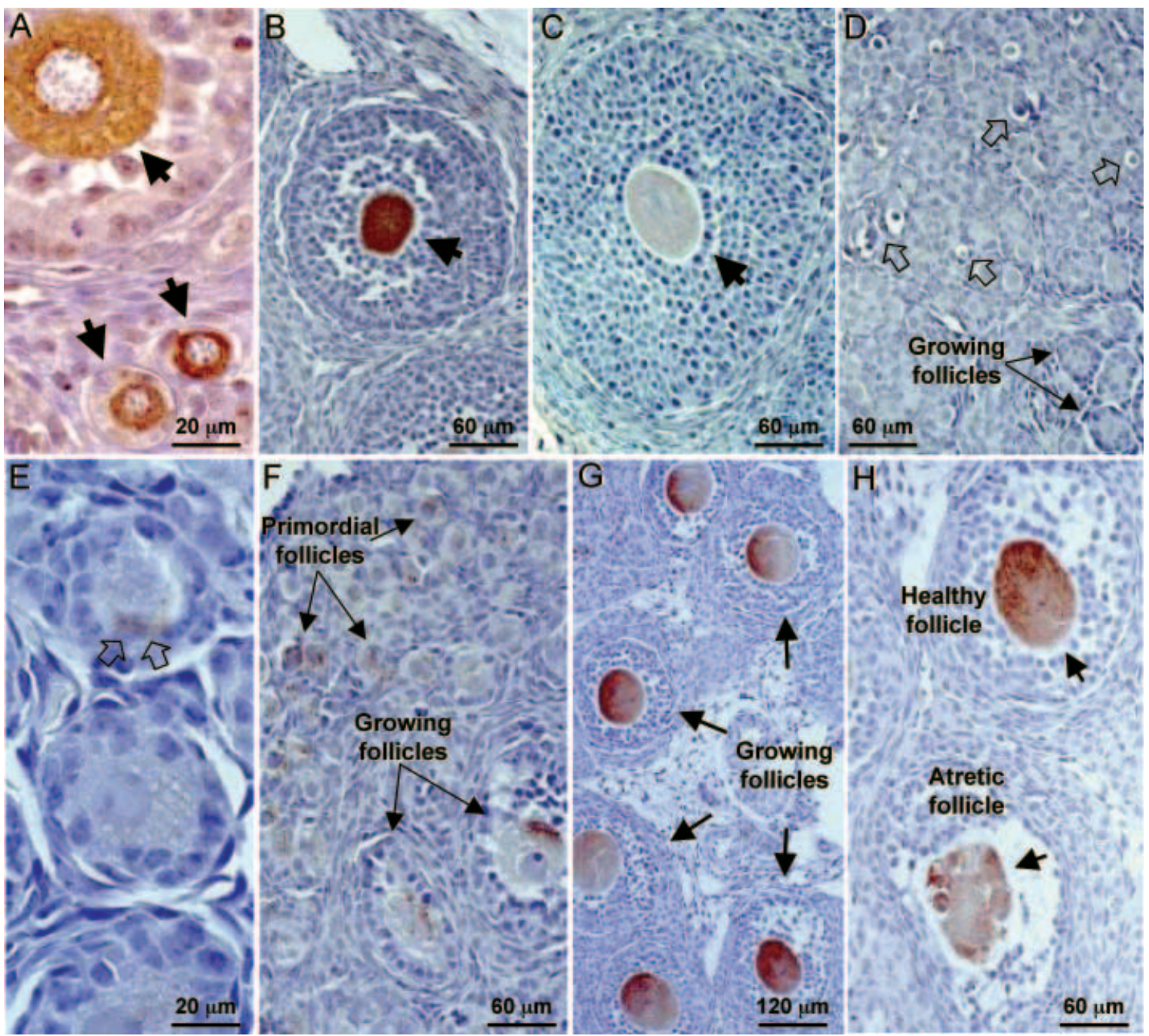

Figure $1 \mathrm{Grx}$ immunostaining in the rat ovary during postnatal development. Immunostaining of the oocyte (solid arrows) cytoplasm was observed in both (A) BH- and (B) PFA-fixed tissues, and was abolished by preincubation of anti-Grx antibodies with the peptide (C). At 3 days of age (D), immunostaining was absent. Degenerating oocytes (empty arrows) were abundant. Immunostaining appeared at 7 days of age $(E)$ in the cytoplasm of some oocytes (empty arrows), showed a punctate pattern at 10 days of age (F), and was strong at 20 days of age $(G)$ in the cytoplasm of the oocytes in both healthy and attretic follicles ( $G$ and $H)$.

Grx concentration was determined by two methods. A direct, 'sandwich' ELISA method and a quantitative Western blot method were developed and optimized. Standard curves were excellent for both methods, as shown in Fig. 4 for Western blot. Grx content in the liver was $18 \pm 0.05 \mu \mathrm{g} / \mathrm{mg}$ by ELISA and $18 \pm 0.01 \mu \mathrm{g} / \mathrm{mg}$ by Western blot, indicating an optimal correlation between both methods, although ELISA produced higher variations between assays. Grx protein content was higher in oestrus than in other phases of the cycle, but was statistically very significant relative to proestrus (Fig. 5). Late proestrus ovaries were also assayed and gave intermediate values, thus indicating that the increase in Grx content is gradual during the transition from proestrus to oestrus (data not shown). The pattern of Grx activity variation along the cycle paralleled that of Grx protein (Fig. 5C). Pseudopregnant rats presented the lowest Grx protein and activity values.

The activity in the livers did not show appreciable variation, further supporting the significance of the variation found in ovaries. Liver contents were around half those found in ovaries.

\section{Discussion}

This is the first study reporting the expression of Grx in the rat ovary during postnatal development and in adult 

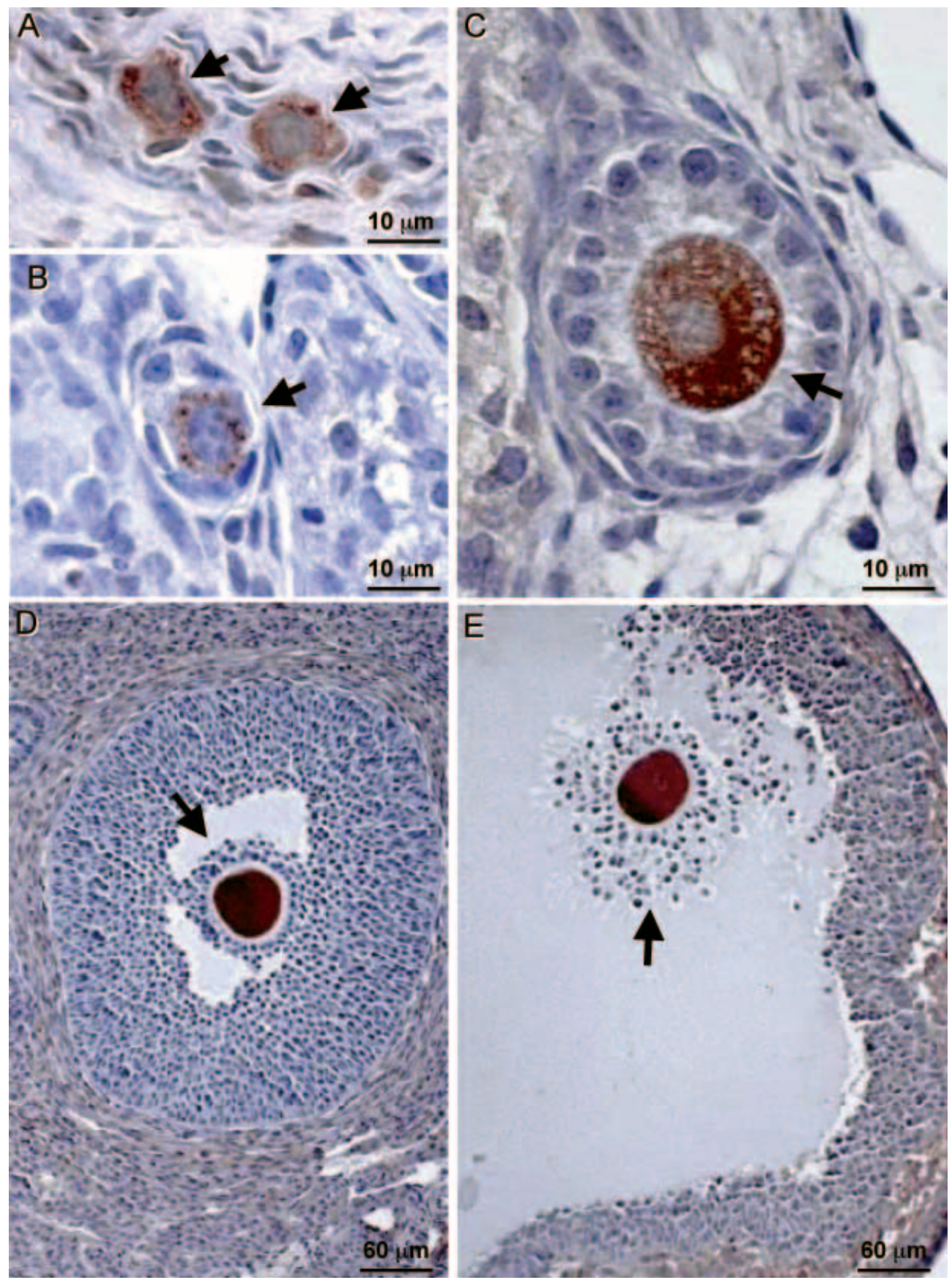

Figure 2 Grx immunostaining in the ovarian follicles of adult cycling rats. Immunostaining of the oocyte cytoplasm (arrows) in (A) primordial and (B) early growing follicles showed a punctate pattern. In larger growing follicles, the intensity of immunostaining increased in parallel to follicle growth (C and D), and was also present in preovulatory follicles (E) at $0200 \mathrm{~h}$ in oestrus immediately before ovulation.

rats through the oestrous cycle and during pseudopregnancy. At the protein level, expression was evidenced by enzymatic activity, immunoblotting and ELISA, and its cellular location was determined by immunohistochemistry using polyclonal antibodies raised against rat Grx. The range of Grx concentration in the rat ovary was similar to that found in the bovine ovary, but for the liver it was roughly half of that in the 
bovine organ (Martinez-Galisteo et al. 1995). Notably, very high levels of Grx expression were found in two ovarian compartments, oocytes and CL, and it showed developmental and cyclic changes.

During postnatal development, Grx expression in oocytes was related to both age and follicle growth. Immunostaining was completely absent at 3 and 5 days of age, in spite of the presence of early growing follicles, whereas clear-cut immunostaining was present at 10 days of age in the oocytes of both primordial and early growing follicles. This clearly indicates that Grx expression is age related. In addition, Grx immunostaining in the oocytes increased in parallel with follicle growth from 10 days of age onward, being maintained throughout follicle development. This prominent presence of Grx in the rat oocyte, together with its absence from the theca and granulosa layers of growing follicles, agrees with similar results found previously in bovine material (Rozell et al. 1993).

Given the importance of the redox status in oocyte biology, a straightforward explanation of the conspicuous presence of Grx in the oocyte relies on the well-documented role of Grx as part of the cellular antioxidant defences. In general, ROS have been reported to have deleterious effects on mammalian germ cells, although a physiological role for ROS has been proposed in mediating successful sperm-oocyte interaction (Aitken et al. 1989) and follicle rupture during ovulation (Miyazaki et al. 1991). Previous studies indicate that GSH is critical to the protection of oocytes from oxidative damage and apoptosis, microtubule polymerization during oocyte meiosis, sperm pronucleus formation after fertilization, and early embryo development (Sawai et al. 1997).

The organization of the cytoskeleton, in particular microtubules and microfilaments, is well known to be involved in the regulation of the dynamic events taking place during oocyte maturation and fertilization in mammals (Sun et al. 2001). G-actin is moderately glutathionylated at Cys374 under normal in vitro growth conditions in human A431 cells, and deglutathionylation facilitates polymerization to form $\mathrm{F}$-actin (Wang et al. 2001). It has recently been confirmed that growth factor-induced actin polymerization, translocation and reorganization near the cell periphery in mouse NIH 3T3 cells depend on glutathionylation/deglutathionylation and are regulated in part by Grx (Wang et al. 2003). The antioxidant action of Grx in the oocyte might thus be essential for oocyte protection from ROS produced during ovulation. Is this action particularly focused on the proper assembly of the cytoskeleton, which is necessary for oocyte maturation? This is an interesting question, the answer to which would open the door to further investigation.

The loss of germ cells in the ovary (oocyte attrition) during early postnatal development has been repeatedly reported, and the pattern of cell death corresponds to programmed cell death (Reynaud \& Driancourt 2000). However, the factors controlling this process are not fully understood. It is worthy of note that degenerating oocytes were particularly abundant on the first days of postnatal life (Gaytan et al. 1998) in coincidence with the absence of Grx expression. Although oocyte attrition occurs throughout female fertile life, massive oocyte loss is limited to the first postnatal days. It is well established that enhancement of GSH content in oocytes protects them from oxidative stress-induced apoptosis during in vitro maturation (Tatemoto et al. 2000, 2001). It has also been shown that Grx binds to apoptosis-signal-regulating kinase (ASK1), thus preventing the onset of cytokine- and stress-induced apoptosis (Song et al. 2002). Moreover, cells overexpressing Grx are more resistant to cadmium-induced apoptosis (Chrestensen et al. 2000). It is tempting to speculate that Grx expression in oocytes could also be involved in the control of oocyte attrition by blockade of the apoptotic pathway.

In our study, Grx expression was present in the oocytes of attretic follicles from 20 days of age onward, a result that may seem contradictory to the above discussion. However, it should be pointed out that this 'adult-type' follicular atresia follows a distinctive pathway in which the oocyte does not show apoptosis, and even undergoes parthenogenetic cell divisions. Actually, follicle atresia in adult rats seems to be determined by the apoptosis of granulosa cells, rather than by primary oocyte demise (Gaytan et al. 1998). This would explain the abundance of antiapoptotic Grx in the oocytes of attretic follicles.

Another important thiol oxidoreductase protein, thioredoxin (Trx), has been studied in the mouse female reproductive organs. It has been found to correlate with Grx in that Trx also increases during the oestrous phase of the cycle (Osborne et al. 2001). However, unlike Grx, Trx does not localize in the oocyte, but it is prominent in both healthy and attretic follicles (Rozell et al. 1985, Iwai et al. 1992, Osborne et al. 2001). These reciprocal localizations indicate that the Trx and Grx systems play

\footnotetext{
Figure 3 Grx immunostaining throughout the corpus luteum $(C L)$ life span. In $C L$ of the current cycle (A), immunostaining was limited to the scarce infiltrating macrophages (arrows). In oestrus (B and $\mathrm{C}$ ), the $\mathrm{CL}$ of the previous cycle showed strong Grx immunostaining in infiltrating macrophages (black arrows in C), some of them showing mitotic figures (asterisk in C), whereas steroidogenic cells showed weak immunostaining (empty arrows in C). Two (D) or more (E) cycles-old regressing CL showed increasing Grx immunostaining with heterogeneous distribution among steroidogenic luteal cells.
} 


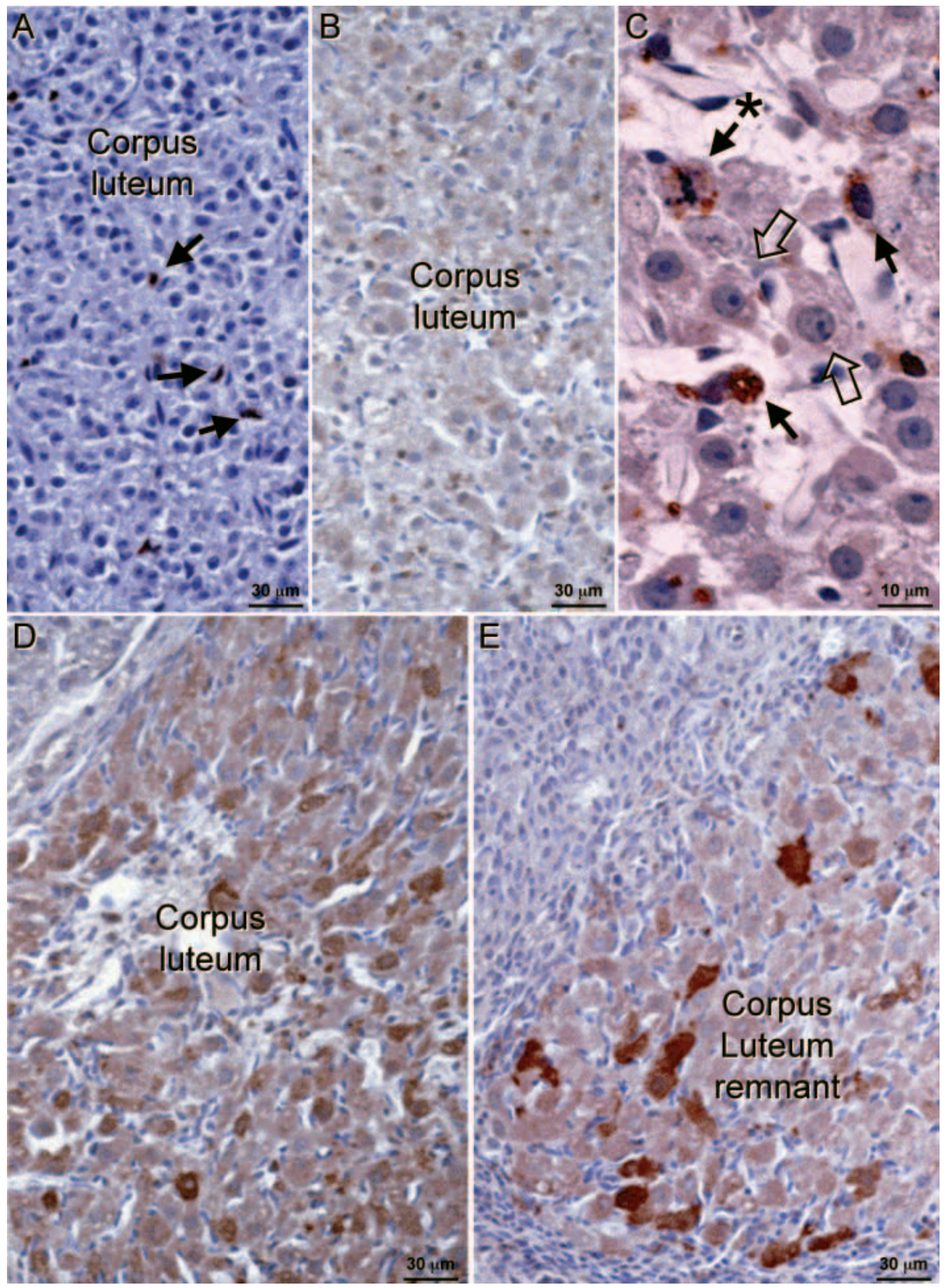


(A)

$$
\begin{array}{lllllll}
\text { ng Grx } & 1,25 & 2,5 & 5 & 10 & 20 & 40
\end{array}
$$

(B)

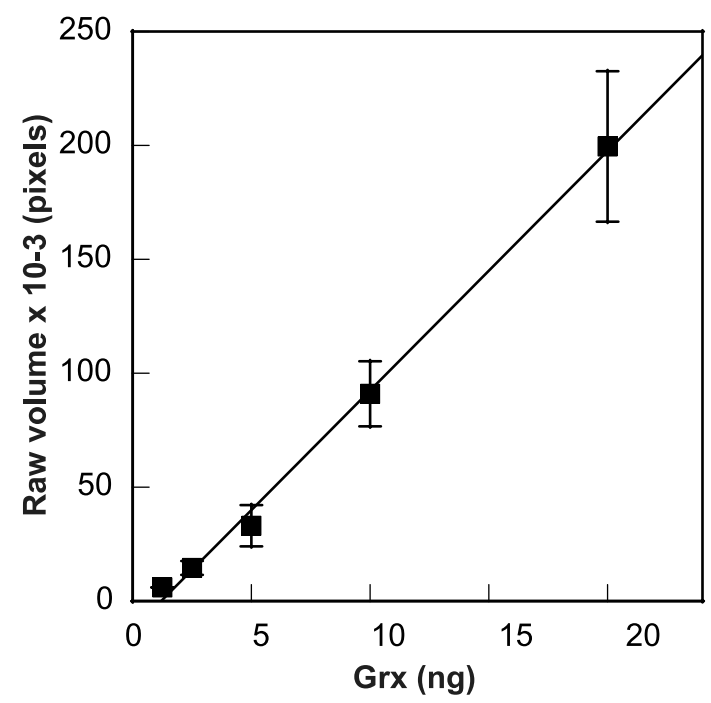

Figure 4 Quantification of Grx by Western blot. The indicated amounts of pure rat Grx were loaded onto acrylamide gels, and after electrophoresis and electrotransfer to nitrocellulose, the membrane was developed with immunoaffinity-purified anti-rat Grx. (A) Image of chemiluminiscence emission. (B) Plot of measured intensity versus amount of Grx; data are the mean \pm S.D. $(n=3)$. complementary roles in the regulation of redox events during normal reproductive functioning in the ovary.

As a whole, the finding of a high level of Grx in the oocyte fits well with the high contents of GSH (Gardiner \& Reed 1994) and GSH reductase (Kaneko et al. 2001) found by others in the same cells, thus confirming the prominent role of the GSH-Grx system in the maintenance of oocyte redox homeostasis, where the metabolic pathways leading to NADPH production are also enhanced during sperm entrance (Urner \& Sakkas 1999) (Fig. 6).

Oxidative stress and apoptosis have been thought to play a key role in steroidogenic cell death during CL regression (Carlson et al. 1993). In the present study, steroidogenic cells were heterogeneous with respect to Grx expression during structural luteolysis, and a reciprocal relationship between Grx immunostaining intensity and steroidogenic cell apoptosis was observed. Thus, steroidogenic cells containing higher Grx concentrations are those surviving the apoptotic bursts triggered by the preovulatory prolactin surge at each transition from proestrus to oestrus. This is not surprising since Grx is well known for its antioxidant and antiapoptotic actions (Chrestensen et al. 2000, Daily et al. 2001). Moreover, immunostaining intensity in Grx-positive cells increased during the transition from proestrus to oestrus in regressing CL, in parallel with the age of the CL remnants.

In addition to oocytes, steroidogenic cells and infiltrating macrophages, basal concentrations of Grx
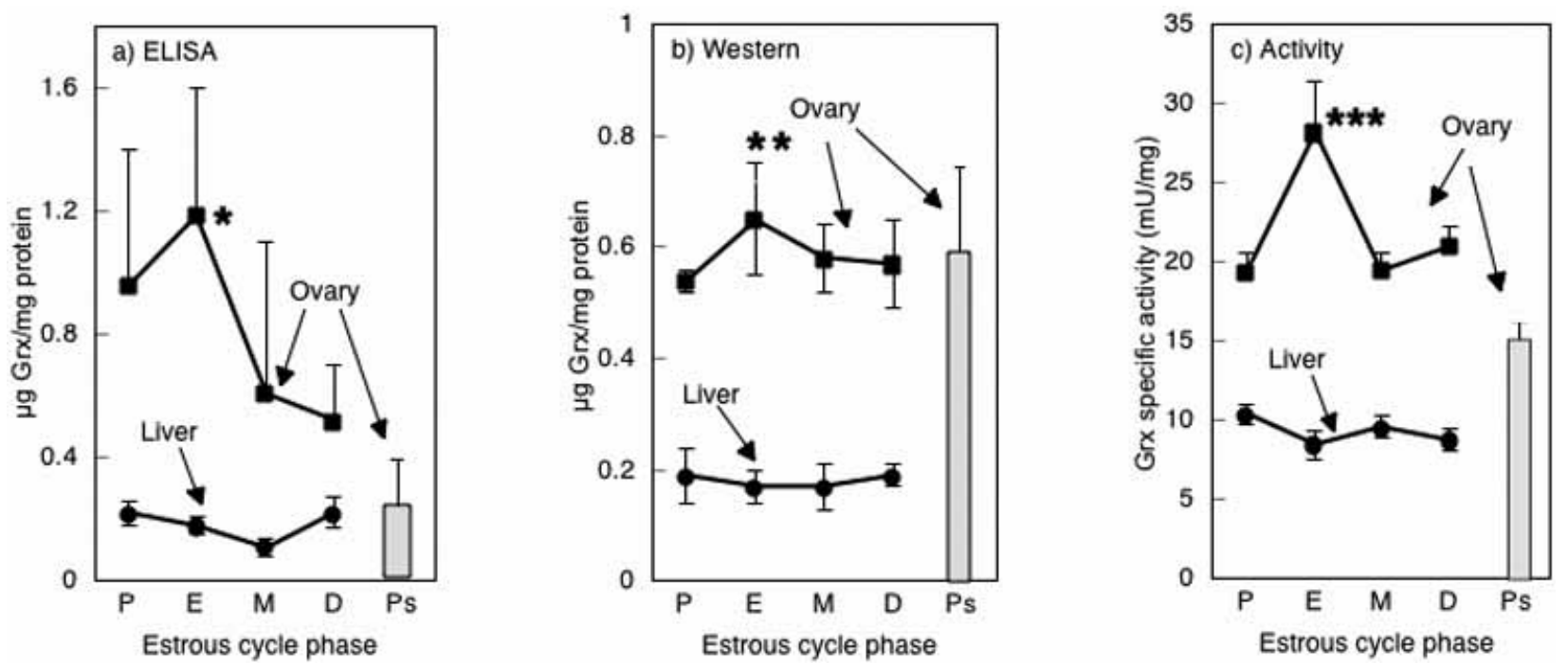

Figure 5 Determination of Grx in ovary and liver of adult cycling rats. The concentration of Grx was determined in extracts of ovaries and livers obtained in four different phases of the oestrous cycle as well as in the ovary of pseudopregnant rats. The data are presented as $\mu \mathrm{g}$ of Grx protein per mg of total protein. (A) Quantification by ELISA; data from one experiment; *statistically significant relative to dioestrus $(P<0.5 ; n=3)$. (B) Quantification by Western blot; data from three different experiments; ** statistically significant relative to proestrus $(P<0.01 ; n=8)$. (C) Specific activity as determined by the standard HED assay; data from three different experiments; ${ }^{* * *}$ statistically significant relative to proestrus $(P<0.001 ; n=6)$. P: proestrus; E: oestrus; M: metaoestrus; D: dioestrus; Ps: pseudopregnant. 


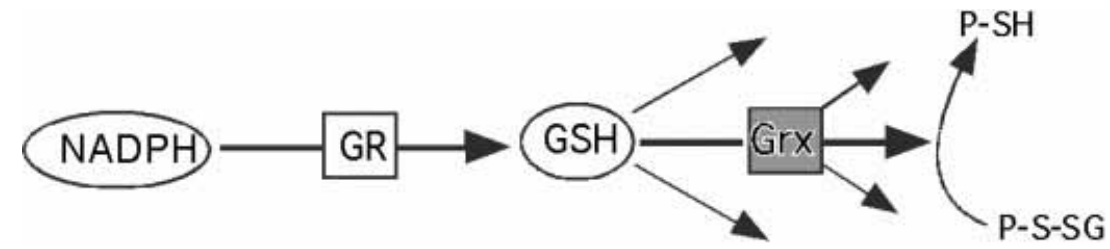

Figure 6 The Grx system. The scheme shows the flow of reducing power from NADPH to oxidatively affected biomolecules in order to maintain the cellular redox homeostasis. GSH is recycled by GSH reductase (GR) so that GSH can exert its reducing action at different processes through specific peroxidases, transferases or Grx. Among other actions, Grx is known to catalyse the recovery of protein thiols (P-SH) in glutathionylated proteins (P-S-SG) that would be otherwise favoured under oxidative stress conditions. All the components of this system seem to be enhanced in mature oocytes (see text for further explanation).

below the detection threshold of the immunohistochemical technique used in this study are also likely to occur widely in other ovarian cells, given the ubiquitous nature of Grx. The sensitive quantitative biochemical methods applied to the whole ovary confirm that this is really the case and extend this concept to ovaries of pseudopregnant rats, where roughly similar basal levels of Grx were found. Interestingly, a rise in total ovarian Grx content during transition from proestrus to oestrus was revealed by these quantitative methods, whereas the histochemical data point to a restricted set of cell types that would be responsible for this augmentation, namely, a fraction of steroidogenic cells that avoid apoptosis and escape the luteolytic path after ovulation and a growing population of infiltrating Grx-positive macrophages in CL of the previous cycle. The finding of basal Grx concentrations in pseudopregnant rats, in which the CL of pseudopregnancy does not undergo regression, agrees with this explanation.

Grx staining of luteal cells during CL regression, but not during formation or maintenance, could erroneously indicate a role for Grx in cell death instead of survival. However, it should be stressed that it is precisely in surviving cells that Grx is present. These cells contribute to total Grx increase in the ovary during the transition from proestrus to oestrus. The increased expression of Grx could be due to activation of regulatory elements present in the promoter of Grx (Park \& Levine 1997) by downstream components of signalling cascades triggered by hormones.

In summary, the pattern of Grx expression in the rat ovary supports a role for this protein in the maturation of the oocytes and survival of a small but significant population of luteal cells, presumably by protection from apoptosis and oxidative damage. The presence of persistent cells that resist several rounds of structural luteolysis poses many questions about this protein's function in the rat endocrine system that should be answered by further experiments.

\section{Acknowledgements}

This research was financed by grants from the Spanish Ministerio de Educación y Cultura (BFI2002-00755 and BFI2002-00485) and from Plan Andaluz de Investigación, Junta de Andalucía (CVI-216). The authors declare that there is no conflict of interest that would prejudice the impartiality of this scientific work

\section{References}

Aitken RJ, Clarkson JS \& Fishel S 1989 Generation of reactive oxygen species, lipid peroxidation, and human sperm function. Biology of Reproduction 41 183-197.

Bandyopadhyay S, Starke DW, Mieyal JJ \& Gronostajski RM 1998 Thioltransferase (glutaredoxin) reactivates the DNA-binding activity of oxidation-inactivated nuclear factor I. Foumal of Biological Chemistry 273 392-397.

Behrman HR, Kodaman PH, Preston SL \& Gao S 2001 Oxidative stress and the ovary. Fournal of the Society for Gynecologic Investigation $\mathbf{8}$ S40-42.

Bradford MM 1976 A rapid and sensitive method for the quantitation of microgram quantities of protein utilizing the principle of protein-dye binding. Analytical Biochemistry 72 248-254.

Carlson JC, Wu XM \& Sawada M 1993 Oxygen radicals and the control of ovarian corpus luteum function. Free Radical Biology and Medicine 14 79-84.

Chrestensen CA, Starke DW \& Mieyal JJ 2000 Acute cadmium exposure inactivates thioltransferase (glutaredoxin), inhibits intracellular reduction of protein-glutathionyl-mixed disulfides, and initiates apoptosis. Fournal of Biological Chemistry 275 26556-26565.

Daily D, Vlamis-Gardikas A, Offen D, Mittelman L, Melamed E, Holmgren A \& Barzilai A 2001 Glutaredoxin protects cerebellar granule neurons from dopamine-induced apoptosis by activating NF-kappa B via Ref-1. Fournal of Biological Chemistry 276 1335-1344.

García-Pardo L, Granados MD, Gaytán F, Padilla CA, Martínez-Galisteo E, Morales C, Sánchez-Criado JE \& Bárcena JA 1999 Immunolocalization of glutaredoxin in the human corpus luteum. Molecular Human Reproduction 5 914-919.

Gardiner CS \& Reed DJ 1994 Status of glutathione during oxidant-induced oxidative stress in the preimplantation mouse embryo. Biology of Reproduction 51 1307-1314. 
Gaytan F, Morales C, Bellido C, Aguilar E \& Sanchez-Criado JE 1998 Ovarian follicle macrophages: is follicular atresia in the immature rat a macrophage-mediated event? Biology of Reproduction 58 52-59.

Gaytan F, Bellido C, Morales C \& Sanchez-Criado JE 2001 Luteolytic effect of prolactin is dependent on the degree of differentiation of luteal cells in the rat. Biology of Reproduction $\mathbf{6 5}$ 433-441.

Gaytan F, Tarradas E, Morales C, Bellido G \& Sanchez-Criado JE 2002 Morphological evidence for uncontrolled proteolytic activity during the ovulatory process in indomethacin-treated rats. Reproduction 123 639-649.

Gladyshev VN, Liu A, Novoselov SV, Krysan K, Sun QA, Kryukov VM, Kryukov GV \& Lou MF 2001 Identification and characterization of a new mammalian glutaredoxin (thioltransferase) Grx2. Journal of Biological Chemistry $27630374-30380$.

Gravina SA \& Mieyal JJ 1993 Thioltransferase is a specific glutathionyl mixed disulfide oxidoreductase. Biochemistry 32 3368-3376.

Harboe HMG \& Ingild A 1983 Immunization, isolation of immunoglobulins and antibody titer determination. In Handbook of Immunoprecipitation-in-Gel Techniques, pp 345-351. Ed NH Axelsen. Oxford: Blackwell Scientific.

Hirota K, Matsui M, Murata M, Takashima Y, Cheng FS, Itoh T, Fukuda K \& Yodoi J 2000 Nucleoredoxin, glutaredoxin, and thioredoxin differentially regulate NF-kappaB, AP-1, and CREB activation in HEK293 cells. Biochemical and Biophysical Research Communications 274 177-182.

Holmgren A \& Aslund F 1995 Glutaredoxin. Methods in Enzymology 252 283-292

Iwai T, Fujii S, Nanbu Y, Nonogaki H, Konishi I, Mori T, Masutani H \& Yodoi J 1992 Expression of adult T-cell leukaemia-derived factor, a human thioredoxin homologue, in the human ovary throughout the menstrual cycle. Virchowes Archiv A Pathological Anatomy and Histopathology 420 213-217.

Jacobson MD 1996 Reactive oxygen species and programmed cell death. Trends in Biochemical Sciences 21 83-86.

Kaneko T, Iuchi Y, Kawachiya S, Fujii T, Saito H, Kurachi H \& Fujii J 2001 Alteration of glutathione reductase expression in the female reproductive organs during the estrous cycle. Biology of Reproduction 65 1410-1416.

Lundberg M, Johansson C, Chandra J, Enoksson M, Jacobsson G, Ljung J, Johansson M \& Holmgren A 2001 Cloning and expression of a novel human glutaredoxin (Grx2) with mitochondrial and nuclear isoforms. Fournal of Biological Chemistry 276 26269-26275.

Luthman M \& Holmgren A 1982 Glutaredoxin from calf thymus. Purification to homogeneity. Fournal of Biological Chemistry 257 6686-6690.

Lysell J, Stjernholm Vladic Y, Ciarlo N, Holmgren A \& Sahlin L 2003 Immunohistochemical determination of thioredoxin and glutaredoxin distribution in the human cervix, and possible relation to cervical ripening. Gynecological Endocrinology 17 303-310.

Martinez-Galisteo E, Padilla CA, Holmgren A \& Barcena JA 1995 Characterization of mammalian thioredoxin reductase, thioredoxin and glutaredoxin by immunochemical methods. Comparative Biochemistry and Physiology B-Biochemistry and Molecular Biology 111 17-25.

Miesel R, Drzejczak PJ \& Kurpisz M 1993 Oxidative stress during the interaction of gametes. Biology of Reproduction 49 918-923.

Miyazaki T, Sueoka K, Dharmarajan AM, Atlas SJ, Bulkley GB \& Wallach EE 1991 Effect of inhibition of oxygen free radical on ovulation and progesterone production by the in vitro perfused rabbit ovary. Fournal of Reproduction and Fertility 91 207-212.

Osborne LJ, Tonissen KF, Tang VH \& Clarke FM 2001 Expression and localisation of thioredoxin in mouse reproductive tissues during the oestrous cycle. Molecular Reproduction and Development 58 359-367.
Osman P 1985 Rate and course of atresia during follicular development in the adult cyclic rat. Fournal of Reproduction and Fertility 73 261-270.

Padilla CA, Martinez-Galisteo E, Barcena JA, Spyrou G \& Holmgren A 1995 Purification from placenta, amino acid sequence, structure comparisons and cDNA cloning of human glutaredoxin. European Fournal of Biochemistry 227 27-34.

Padilla CA, Spyrou G \& Holmgren A 1996 High-level expression of fully active human glutaredoxin (thioltransferase) in E. coli and characterization of Cys7 to Ser mutant protein. FEBS Letters 378 69-73.

Park JB \& Levine M 1997 The human glutaredoxin gene determination of its organization, transcription start point, and promoter analysis. Gene 197 189-193.

Pedrajas JR, Porras P, Martinez-Galisteo E, Padilla CA, Miranda-Vizuete A \& Barcena JA 2002 Two isoforms of Saccharomyces cerevisiae glutaredoxin 2 are expressed in vivo and localize to different subcellular compartments. Biochemical fournal $\mathbf{3 6 4} 617-623$.

Porras P, Pedrajas JR, Martinez-Galisteo E, Padilla CA, Johansson C, Holmgren A \& Barcena JA 2002 Glutaredoxins catalyze the reduction of glutathione by dihydrolipoamide with high efficiency. Biochemical and Biophysical Research Communications 295 1046-1051.

Reynaud K \& Driancourt MA 2000 Oocyte attrition. Molecular and Cellular Endocrinology 163 101-108.

Rozell B, Hansson HA, Luthman M \& Holmgren A 1985 Immunohistochemical localization of thioredoxin and thioredoxin reductase in adult rats. European Fournal of Cell Biology 38 79-86.

Rozell B, Barcena JA, Martinez-Galisteo E, Padilla CA \& Holmgren A 1993 Immunochemical characterization and tissue distribution of glutaredoxin (thioltransferase) from calf. European Fournal of Cell Biology 62 314-323.

Sanchez-Criado J \& Rothchild I 1986 The relation between the effects of hysterectomy, decidual tissue, prolactin, or luteinizing hormone $(\mathrm{LH})$ and the ability of indomethacin to prevent luteolysis in rats bearing LH-dependent corpora lutea. Endocrinology $1191750-1756$.

Sawai K, Funahashi H \& Niwa K 1997 Stage-specific requirement of cysteine during in vitro maturation of porcine oocytes for glutathione synthesis associated with male pronuclear formation. Biology of Reproduction 57 1-6.

Shaw W, Smith J, Spierto FW \& Agnese ST 1977 Linearization of data for saturation-type competitive protein binding assay and radioimmunoassay. Clinica Chimica Acta 76 15-24.

Sies H 1999 Glutathione and its role in cellular functions. Free Radical Biology and Medicine 27 916-921.

Song JJ, Rhee JG, Suntharalingam M, Walsh SA, Spitz DR \& Lee YJ 2002 Role of glutaredoxin in metabolic oxidative stress. Glutaredoxin as a sensor of oxidative stress mediated by $\mathrm{H}_{2} \mathrm{O}_{2}$. Journal of Biological Chemistry 277 46566-46575.

Stavreus-Evers A, Masironi B, Landgren BM, Holmgren A, Eriksson H \& Sahlin L 2002 Immunohistochemical localization of glutaredoxin and thioredoxin in human endometrium: a possible association with pinopodes. Molecular Human Reproduction $\mathbf{8}$ 546-551.

Sun QY, Lai L, Park KW, Kuhholzer B, Prather RS \& Schatten H 2001 Dynamic events are differently mediated by microfilaments, microtubules, and mitogen-activated protein kinase during porcine oocyte maturation and fertilization in vitro. Biology of Reproduction 64 879-889.

Takashima Y, Hirota K, Nakamura H, Nakamura T, Akiyama K, Cheng FS, Maeda M \& Yodoi J 1999 Differential expression of glutaredoxin and thioredoxin during monocytic differentiation. Immunology Letters 68 397-401.

Tanaka M, Miyazaki T, Tanigaki S, Kasai K, Minegishi K, Miyakoshi K, Ishimoto H \& Yoshimura Y 2000 Participation of reactive oxygen species in PGF2 alpha-induced apoptosis in rat luteal cells. Fournal of Reproduction and Fertility 120 239-245. 
Tatemoto H, Sakurai N \& Muto N 2000 Protection of porcine oocytes against apoptotic cell death caused by oxidative stress during In vitro maturation: role of cumulus cells. Biology of Reproduction 63 805-810.

Tatemoto H, Ootaki K, Shigeta K \& Muto N 2001 Enhancement of developmental competence after in vitro fertilization of porcine oocytes by treatment with ascorbic acid 2-O-alphaglucoside during in vitro maturation. Biology of Reproduction 65 1800-1806.

Tilly JL 1996 Apoptosis and ovarian function. Reviews of Reproduction 1 162-172.

Towbin H, Staehelin T \& Gordon J 1979 Electrophoretic transfer of proteins from polyacrylamide gels to nitrocellulose sheets: procedure and some applications. PNAS 76 4350-4354.
Urner F \& Sakkas D 1999 Characterization of glycolysis and pentose phosphate pathway activity during sperm entry into the mouse oocyte. Biology of Reproduction 60 973-978.

Wang J, Boja ES, Tan W, Tekle E, Fales HM, English S, Mieyal JJ \& Chock PB 2001 Reversible glutathionylation regulates actin polymerization in A431 cells. Fournal of Biological Chemistry 276 47763-47766.

Wang J, Tekle E, Oubrahim H, Mieyal JJ, Stadtman ER \& Chock PB 2003 Stable and controllable RNA interference: investigating the physiological function of glutathionylated actin. PNAS $\mathbf{1 0 0}$ 5103-5106.

Received 3 December 2004

Accepted 27 January 2005

Made available online as an Accepted Preprint 7 February 2005 